\title{
Epigenetically silenced microRNAs in gastric cancer: Functional analysis and identification of their target genes
}

\author{
JIN-HAN BAE $^{1 *}$, MYOUNG JOO KANG $^{2 *}$, KWANG-MO YANG $^{1}$, TAE-OH KIM ${ }^{2}$ and JOO MI YI ${ }^{1}$ \\ ${ }^{1}$ Research Center, Dongnam Institute of Radiological and Medical Sciences (DIRAMS), \\ Busan 619-953; ${ }^{2}$ Department of Internal Medicine, Inje University \\ Haeundae Paik Hospital, Busan 612-896, Republic of Korea
}

Received April 2, 2015; Accepted May 11, 2015

DOI: $10.3892 /$ or.2015.4036

\begin{abstract}
RNAs (miRNAs), which are small non-coding RNA molecules, can participate in diverse biological functions and act as oncogenes or tumor suppressors by inhibiting target gene expression. The alteration of miRNA expression is observed in many types of human cancers and has been implicated in carcinogenesis. Since miRNAs have been known to be downregulated in most cancer types, there is growing evidence that several miRNAs are downregulated by DNA hypermethylation. Here, we determined that MIR219.2, MIR663B and MIR1237 were transcriptionally silenced by DNA hypermethylation in human gastric cancer cell lines. Moreover, we demonstrated the functional roles of these epigenetically silenced miRNAs by ectopically expressing them in gastric cancer cells, which caused the suppression of growth and proliferation. In addition, wound closure, cell migration, and invasion were significantly reduced in AGS cells following transfection with MIR219.2, MIR663B or MIR1237 mimics. Notably, epithelial-to-mesenchymal transition (EMT)-associated proteins were decreased in response to ectopic expression of these miRNAs, supporting the notion that these miRNAs have a tumor-suppressive effect in gastric cancer. We finally predicted the targets of these miRNAs and identified several candidate genes, the expression levels of which were significantly downregulated by ectopic expression of MIR219.2, MIR663B or MIR 1237 mimics in the
\end{abstract}

Correspondence to: Dr Joo Mi Yi, Research Center, Dongnam Institute of Radiological and Medical Sciences (DIRAMS), Busan 619-953, Republic of Korea

E-mail: jmyi@dirams.re.kr

Dr Tae-Oh Kim, Department of Internal Medicine, Inje University Haeundae Paik Hospital, Busan 612-896, Republic of Korea

E-mail:kto0440@paik.ac.kr

*Contributed equally

Key words: DNA methylation, 5-aza-2'-deoxycytidine, microRNA, gastric cancer, tumor-suppressive effect gastric cancer cell lines. Our study provides strong evidence that these miRNAs are transcriptionally regulated by DNA methylation in gastric cancer and have tumor-suppressive roles by decreasing the mesenchymal traits in cancer as well as by targeting cancer-associated genes.

\section{Introduction}

microRNAs (miRNAs) are small non-coding RNAs that regulate gene expression post-transcriptionally by binding to complementary sequences in the 3'-untranslated region of messenger RNAs (mRNAs) (1). Approximately $30 \%$ of human genes are under miRNA regulation. Not only does each miRNA regulate many genes, but also each gene is regulated by many miRNAs $(2,3)$. Many miRNAs are highly conserved among species and play critical roles in a variety of biological processes, including development, differentiation, proliferation, apoptosis and stem cell maintenance $(1,4,5)$. Consistent with their roles in these processes, many studies have shown widespread alteration of miRNA expression patterns in cancer $(6,7)$. Indeed, downregulation of a subset of miRNAs is a commonly observed feature noted in cancer, suggesting that these molecules may act as tumor suppressors (8). Many other recent studies show that dysfunction of miRNAs is related to chronic lymphocytic leukemia and several solid tumors, including colon, lung, breast, gastric and liver cancers (1,9-12). Furthermore, disruption of miRNA biogenesis in various types of cancer has been implicated in a variety of mechanisms, such as genomic deletion, mutation, epigenetic silencing and miRNA processing defects (13-16).

Gastric cancer is one of the most common causes of death from cancer among men and women worldwide (17). To date, we and many other researchers have identified a wide variety of tumor-suppressor genes and other tumor-related genes that are silenced by abnormal DNA methylation in gastric cancer $(18,19)$. In addition, it was recently shown that epigenetic mechanisms are involved in the alteration of several miRNA genes in gastric cancer $(18,20)$, although little is known concerning the dysregulation of miRNAs in this disease. Previously, several novel DNA methylation-regulated miRNAs were classified in colon cancer cells by combining genome-wide DNA methylation and miRNA expression analyses (21). In the present study, we aimed to test the 
epigenetic silencing of three miRNAs (MIR219.2, MIR663B and MIR1237) in gastric cancer and evaluate the phenotypic impact of such epigenetic silencing on gastric cancer.

In short, we found MIR219.2, MIR663B and MIR1237 to harbor dense DNA methylation in gastric cancer cell lines and that such aberrant DNA hypermethylation correlated with their transcriptional silencing as well as re-expression after 5-aza-2'-deoxycytidine (5-aza-dC) treatment. We also determined that ectopic expression of MIR219.2, MIR663B and MIR 1237 resulted in important biological roles, such as a decrease in cell proliferation, migration and invasion, suggesting that these miRNAs have a tumor-suppressive role in gastric cancer by decreasing epithelial-to-mesenchymal transition (EMT)-associated factors. In addition, we retrieved several target genes regulated by MIR219.2, MIR663B and MIR 1237 using TargetScan and miRBase databases. Finally, we identified the candidate target genes regulated by MIR219.2, MIR663B and MIR1237, suggesting that epigenetic silencing of these miRNAs may be responsible for some important tumor-suppressive characteristics of gastric cancer cells.

\section{Materials and methods}

Cell culture and 5-aza-dC treatments. Five human gastric cancer cell lines (AGS, AZ521, KATO III, NCI-N87 and SNU-1) were used in this study and were obtained from the American Type Culture Collection (ATCC; Manassas, VA, USA) and Korea Research Institute of Bioscience and Biotechnology BioResource Center in Korea. The AGS cell line was cultured using Ham's F-12, AZ521 was maintained in MEM medium, KATO III was grown in Iscove's modified Dulbecco's medium (IMDM), and NCI-N87 and SNU-1 were propagated in RPMI-1640 medium (all from WelGene, Daegu, Korea). All cell culture media were supplemented with $10 \%$ fetal bovine serum (FBS; HyClone, Logan, UT, USA) and $1 \%$ antibiotic-antimycotic (Gibco, Grand Island, NY, USA). All cell lines were incubated at $37^{\circ} \mathrm{C}$ with $20 \% \mathrm{O}_{2}$ and $5 \% \mathrm{CO}_{2}$. To investigate the effect of 5-aza-dC treatments, cells were treated with $5 \mu \mathrm{M}$ 5-aza-dC (Sigma, St. Louis, MO, USA) for $72 \mathrm{~h}$.

Tissue samples. The biospecimens and data used in this study were provided by the Inje Biobank of Inje University Busan Paik Hospital, a member of the Korea Biobank Network.

DNA methylation analyses. Primer pairs for methylation analysis were preferentially designed near the putative transcription start site (TSS) in the $5^{\prime} \mathrm{CpG}$ islands of the genes. All methylation-specific primers were designed by MethPrimer (http://www.urogene.org/methprimer). Methylation analyses, including methylation-specific PCR (MSP) and bisulfite sequencing analysis, were performed as previously described (18).

Quantitative real-time RT-PCR ( $q R T-P C R$ ). Total RNA was isolated from human gastric cancer cell lines using TRI-Solution (Bioscience Technology, Kyungsan, Korea) following the manufacturer's instructions. RNA quantity was measured using a NanoDrop 2000/2000c instrument (Thermo Scientific, Rockford, IL, USA), and $1 \mu \mathrm{g}$ of RNA was reverse-transcribed into cDNA using the iScript cDNA Synthesis kit (Bio-Rad, Hercules, CA, USA). For expression studies using RT-PCR, primers were designed using the Open Access Primer3 program (http://frodo.wi.mit.edu/primer3). Quantitative RT-PCR was performed on a C1000 Thermal Cycler (BioRad) using the PCR primers we specifically designed. The expression levels of pri-miRNAs and target genes were normalized to $\beta$-actin levels. $\Delta \Delta \mathrm{Ct}$ method was used for the relative quantification of expression.

miRNA transfection. To ectopically express MIR219.2,MIR663B and MIR1237 in the AGS gastric cancer cell line, cells were transfected with $20 \mathrm{nM}$ hsa-miR-219a-2-3p (MSY0004675), hsamiR-663b (MSY0005867) and hsa-miR-1237 (MSY0005592) miScript mimics, or AllStars Negative Control siRNA (1027281) (all from Qiagen, GmbH, Hilden, Germany) using Lipofectamine 2000 (Invitrogen, Carlsbad, CA, USA) following the manufacturer's instructions.

Cell proliferation and viability assays. Cell proliferation was analyzed using the MTT assay. At $24 \mathrm{~h}$ after transfection of miRNA mimics or the negative control, AGS cells $\left(2 \times 10^{5}\right.$ cells/well $)$ were re-plated in 6-well plates and incubated at $37^{\circ} \mathrm{C}$. After $72 \mathrm{~h}$, the cells were washed twice with phosphate-buffered saline (PBS) and $5 \mathrm{mg} / \mathrm{ml}$ MTT in PBS was added to each well for $4 \mathrm{~h}$. After removing the MTT solution, a solubilization solution (DMSO/EtOH, 1:1 ratio) was added to each well to dissolve the formazan crystals. The absorbance at $570 \mathrm{~nm}$ was measured using a Paradigm microplate reader (Beckman Coulter, Fullerton, CA, USA). After re-plating $\left(5 \times 10^{3}\right.$ cells/well) in 6 -well plates, cell numbers were counted at $24,48,72$ and $96 \mathrm{~h}$.

Wound-healing assay. Mimic or control siRNA-transfected AGS cells were plated overnight to achieve a subconfluent cell monolayer in 6-well plates. Then, a scratch was made in the cell layer with a sterile 200- $\mu 1$ pipette tip, and cultures were washed twice with serum-free medium to remove floating cells. Cells were incubated in culture medium. After $16 \mathrm{~h}$, wound healing was visualized by comparing images using a QImaging QIClick camera system mounted on a phase-contrast Nikon TS100 microscope (Nikon, Melville, NY, USA). The distance traveled by the cells was determined by measuring the wound width at $16 \mathrm{~h}$ and subtracting it from the wound width at $0 \mathrm{~h}$.

Migration and invasion assays. Cell migration was determined using Transwell plates (24-well, $8-\mu \mathrm{m}$ pore size; Corning Costar, Rochester, NY, USA) and the invasion assay was carried out using a Matrigel-coated invasion chamber (24-well, $8-\mu \mathrm{m}$ pore size; Corning Costar). The upper chamber contained cells in specific medium with $1 \%$ FBS, and the lower chamber contained medium with $10 \%$ FBS. Cells were incubated for $16 \mathrm{~h}$ at $37^{\circ} \mathrm{C}$ with $20 \% \mathrm{O}_{2}$ and $5 \% \mathrm{CO}_{2}$. Non-migratory or non-invasive cells were scraped off the upper membrane with a cotton swab. Migratory or invasive cells remaining on the bottom membrane were counted after staining with Giemsa (Sigma). Images were captured using a QIcam image camera system mounted on a Nikon Eclipse 80i microscope (Nikon). 
Western blot analysis. Total cell lysates $(20 \mu \mathrm{g})$ were separated by SDS-PAGE and transferred to PVDF membranes (GE Healthcare Life Sciences, Piscataway, NJ, USA). The membranes were blocked with $5 \%$ milk dissolved in Tris-buffered saline containing $0.02 \%$ Tween-20 and incubated overnight at $4^{\circ} \mathrm{C}$ with specific primary antibodies. The membranes were subsequently incubated with specific horseradish peroxidase-conjugated secondary antibodies. Protein bands were visualized using a Fusion FX5 system (Vilber Lourmat, Eberhardzell, Germany). The following primary antibodies were used: anti-E-cadherin, anti-N-cadherin, anti-Slug and anti-vimentin (all from Santa Cruz Biotechnology, Santa Cruz, CA, USA) and anti- $\beta$-actin (Sigma) antibodies.

Bioinformatic analysis of miRNA target genes. The miRNA target genes were collected from miRBase (http://www.miRbase.org) and TargetScan Human Release 6.2 (http://www.targetscan.org). Sequences of miRNAs were aligned using the BioEdit program (http://www. mbio.ncsu.edu/bioedit/bioedit.html), and, using the University of California Santa Cruz (UCSC) Genome Browser (http://genome.ucsc.edu) and BLAT search, genome locations and matches with $\mathrm{CpG}$ islands were analyzed. To identify the functions and signaling pathways of the target genes, the super-pathway categories within the GeneCards database (http://www.genecards.org/cgi-bin), which included Kyoto Encyclopedia of Genes and Genomes (KEGG) (http://www. kegg.jp/kegg/pathway.html), were used. Gene interaction analyses of miRNA target genes were performed using the GeneMANIA web tool (http://www.genemania.org) and visualized by Cytoscape ver. 3.0.2. Output of the GeneMANIA search followed query-dependent weighting options.

Statistical analyses. Quantified data are expressed as the mean \pm standard deviation (SD) values. Significance testing was conducted via Student's t-test.

\section{Results}

Expression of MIR219.2, MIR663B and MIR1237 are regulated by DNA hypermethylation in gastric cancer cell lines. To investigate whether pri-MIR219.2, pri-MIR663B and pri-MIR1237 were regulated by DNA methylation in gastric cancer, we treated AGS, AZ521, N87, KATO III and SNU-1 gastric cancer cells with the demethylating agent 5-aza-dC to determine whether these miRNAs are re-expressed after 5 -aza-dC treatment by qRT-PCR.

Notably, we observed the re-expression of three miRNAs after 5-aza-dC treatment in only AGS cells; we did not observe any significant re-expression of these miRNAs after 5 -aza-dC treatment in the other cell lines that were tested (Fig. 1). To verify whether these miRNAs are upregulated by DNA methylation changes, we assessed the level of DNA methylation in the proximal region of these mRNAs by MSP in gastric cancer cell lines and bisulfite genomic sequencing in AGS cells.

Using specific primers in their $\mathrm{CpG}$ island region for methylation analyses (Fig. 2A), we evaluated the methylation patterns in five different gastric cancer cell lines. MIR219.2 and MIR663B were completely methylated in most of the
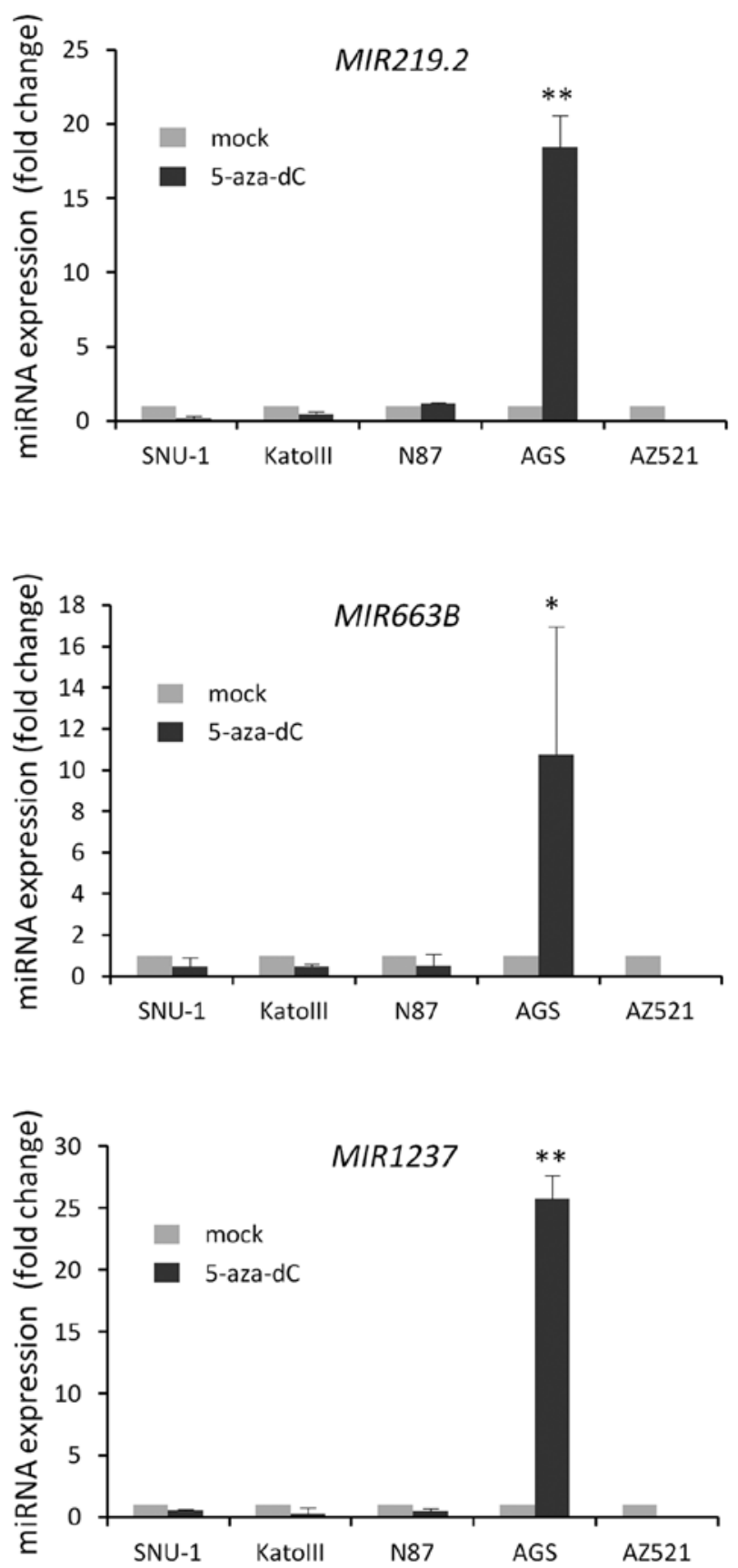

Figure 1. Analysis of MIR219.2, MIR663B and MIR1237 expression in gastric cancer cell lines. Quantitative RT-PCR was performed to assess pri-miRNAs levels in gastric cancer cell lines (AGS, AZ521, KATO III, NCI-N87 and SNU-1) before and after $5 \mu \mathrm{M}$ 5-aza-dC treatment for $72 \mathrm{~h}$. Dark gray bars indicate 5-aza-dC treatment. Relative pri-mRNA levels are shown as mean \pm standard deviation of three independent experiments. ${ }^{*} \mathrm{P}<0.05$ and ${ }^{* *} \mathrm{P}<0.01$, indicate a significant increase in pri-miRNA expression after 5-aza-dC treatment .

gastric cancer cell lines that were tested. MIR 1237 was mostly methylated with a partial methylation pattern compared with the other miRNAs (Fig. 2B). However, we confirmed that these miRNAs are mostly methylated in gastric cancer cell lines, suggesting that these data correlate with the re-expression of miRNAs by 5-aza-dC treatment. We also confirmed the methylation status in the AGS cell line by bisulfite sequencing analysis, showing that most $\mathrm{CpG}$ sites in these miRNAs were methylated (Fig. 2C). To further detect whether MIR219.2, 
A

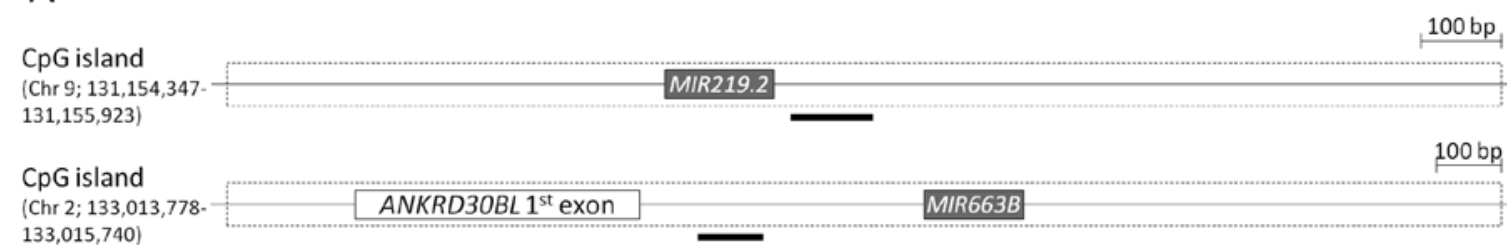

| $\quad$ II || || || \}

\begin{tabular}{l} 
CpG island \\
(Chr $11 ; 64,135,816-$ \\
\hline
\end{tabular}

$64,136,381)$

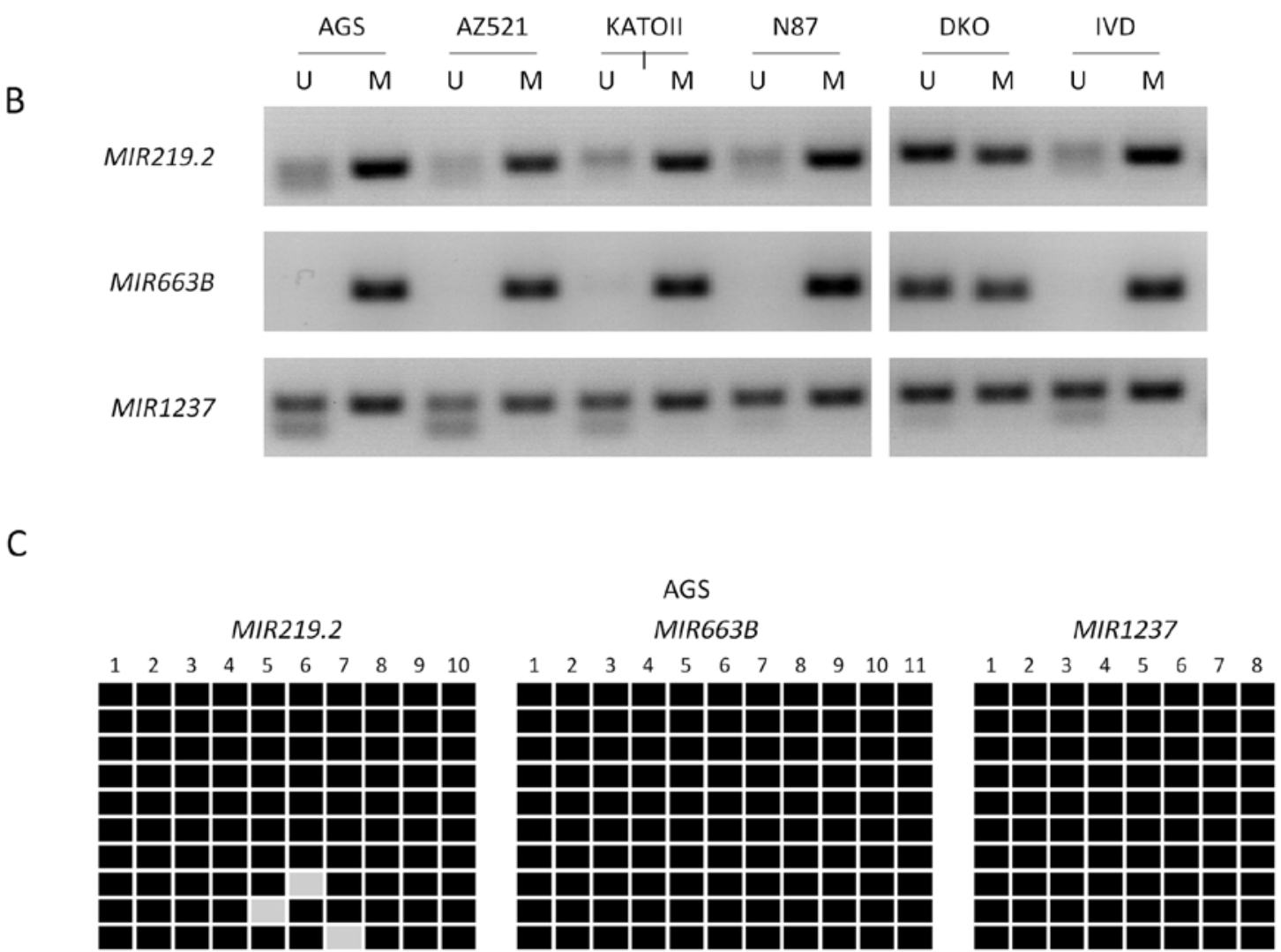

Figure 2. Methylation analyses of MIR219.2, MIR663B and MIR1237 in gastric cancer cell lines. (A) Schematic representation of MIR941 and MIR1247 CpG islands (dotted boxes). Three miRNAs are embedded in the CpG islands (gray boxes). The regions for MSP and bisulfite sequencing analyses are indicated by black bars below the CpG islands. (B) MSP analysis of MIR219.2, MIR663B and MIR1237 in four gastric cancer cell lines. In vitro methylated DNA (IVD), and both DNMT1 and DNMT3B double knockout HCT116 (DKO) cells were used as positive and negative controls, respectively. U and M indicate unmethylated and methylated signals, respectively. (C) Representative bisulfite sequencing analysis was carried out for MIR219.2, MIR663B and MIR1237 in the AGS gastric cancer cell line. Each box represents a CpG dinucleotide. Black boxes represent methylated cytosines, while gray boxes represent unmethylated cytosines.

MIR663B and MIR1237 are methylated in gastric cancer patient tissues, we examined the methylation status of these miRNAs in five gastric cancer primary tissues using bisulfite sequencing analysis. We observed that MIR219.2, MIR663B and $M I R 1237$ were highly methylated in the gastric cancer primary tissues with $95 \%$ (MIR219.2 and MIR663B) and 83\% (MIR1237) of the analyzed CpG sites methylated (Fig. 3). These results suggest that MIR219.2, MIR663B and MIR1237 are densely methylated in gastric cancer cells correlated with transcriptional silencing as well as they are also highly methylated in cancer specimens.
Functional analysis of MIR219.2, MIR663B and MIR1237 in gastric cancer cells. We next tested the biological functions of these epigenetically regulated miRNAs to understand the relevance of their DNA methylation in gastric cancer cells. To determine whether expression of these epigenetically silenced miRNAs would affect cancer cell growth and migration, we transfected AGS cells with miRNA mimics of MIR219.2, MIR663B, MIR 1237 and a non-targeting negative control. Growth curve analysis showed that AGS cell growth was inhibited by $263 \%$ (MIR219.2), 68 (MIR663B) and 69\% (MIR1237) compared to the control (Fig. 4A). Along with growth data, 


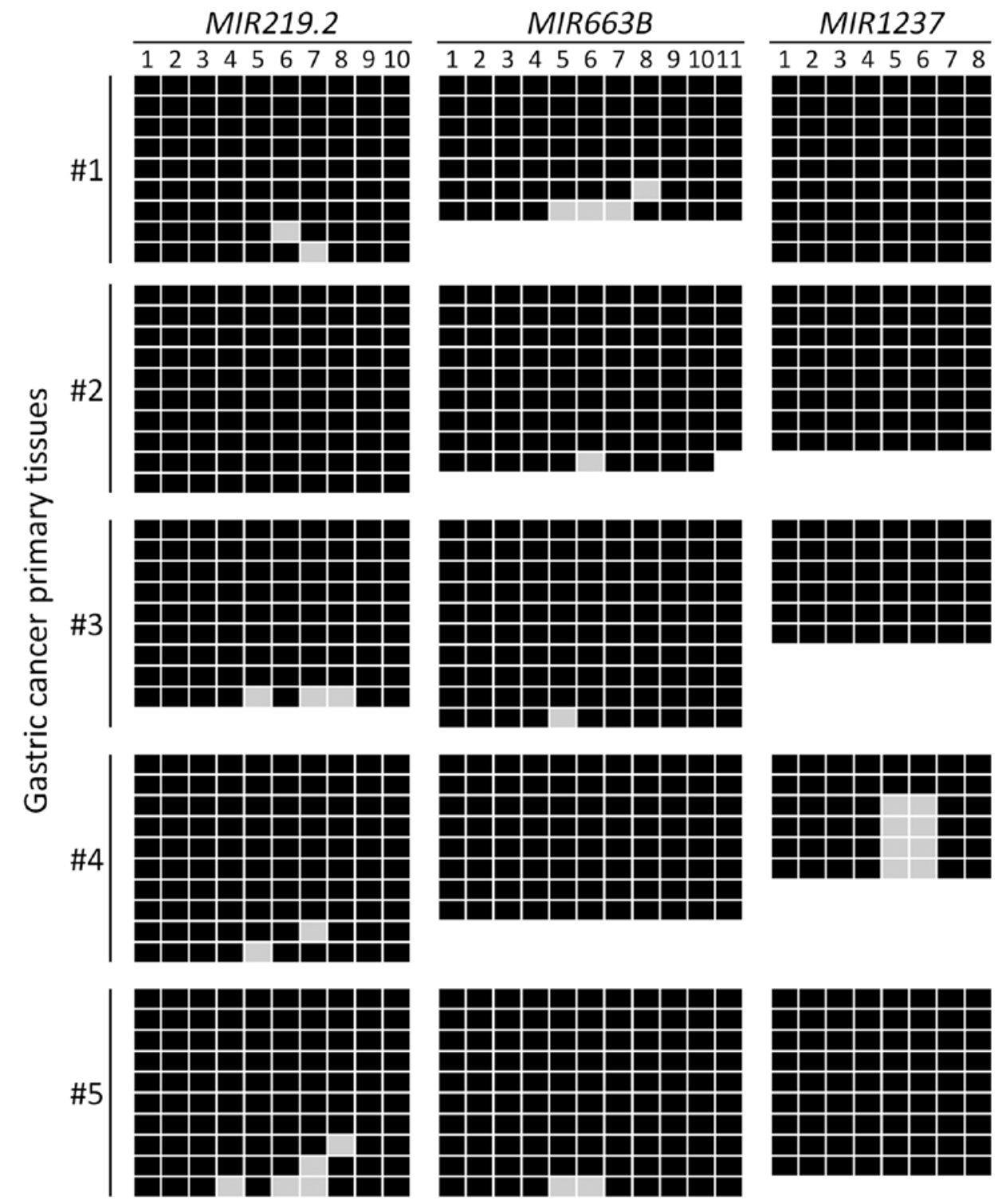

Figure 3. Methylation levels of MIR219..2, MIR663B and MIR1237 in gastric cancer patient primary tissues. Representative bisulfite sequencing analysis was carried out for MIR219.2, MIR663B and MIR1237 in five gastric adenocarcinomas. Each box represents a CpG dinucleotide. Black boxes represent methylated cytosines, while gray boxes represent unmethylated cytosines.

MTT assay demonstrated a 13,11 and $10 \%$ decrease in proliferation following MIR219.2, MIR663B and MIR1237 mimic transfection compare to the control, respectively (Fig. 4B).

Based on the growth curve, we postulated that ectopic expression of MIR219.2, MIR663B and MIR1237 would impact cell migration or invasion. In the wound-healing assays, AGS cells transfected with each miRNA mimic showed less wound closure compared with the mock-treated or control cells (Fig. 4C). These results were further confirmed using Transwell migration and invasion assays (Fig. 4D and $\mathrm{E}$ ). These data indicate that ectopic expression of these miRNAs could affect actual migration- or invasion-associated molecules in cancer. Tumor cell invasion is involved with the loss of cell-cell interaction together with the acquisition of migratory properties and is often associated with EMT (22).

Therefore, we next examined whether ectopic expression of these miRNAs suppresses the migratory and invasive properties of gastric cancer cells through disturbing EMT.
Ectopic expression of miRNAs in the AGS cells decreased mesenchymal cell markers, such as $\mathrm{N}$-cadherin and vimentin, while increasing epithelial cell marker E-cadherin in the AGS cells. These EMT markers are directly regulated by EMT transcription factors, such as Slug. Notably, Slug expression was markedly decreased by ectopic expression of MIR219.2, MIR663B and MIR1237 (Fig. 4F). These data are consistent with the migration and invasion data and strongly support the hypothesis that miRNAs could have a tumor-suppressive effect in gastric cancer by suppressing mesenchymal traits of cancer.

Identification of target genes regulated by MIR219.2, MIR663B and MIR1237. miRNAs modulate gene expression by interacting with their target mRNAs, resulting in mRNA degradation or translational repression. To help us identify potential target genes of MIR219.2, MIR663B and MIR1237 in gastric cancer, target genes were predicted using TargetScan Human 6.2 and miRBase. For MIR219.2, MIR663B and 
A

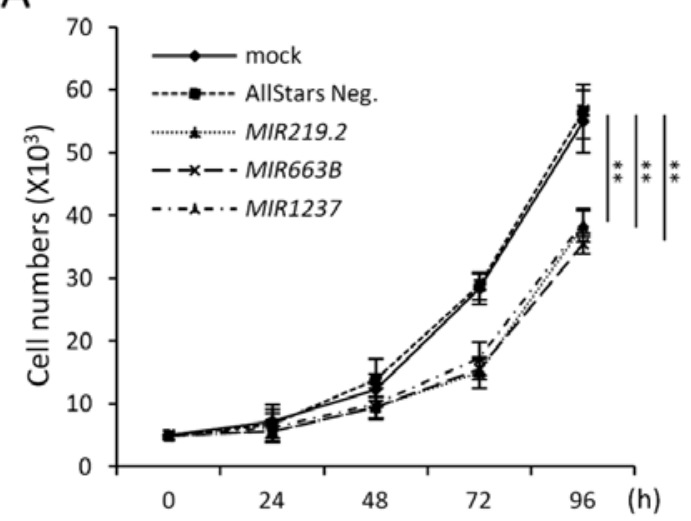

C

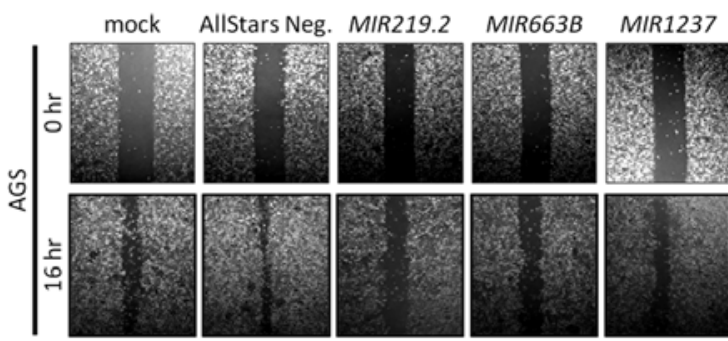

$\mathrm{E}$
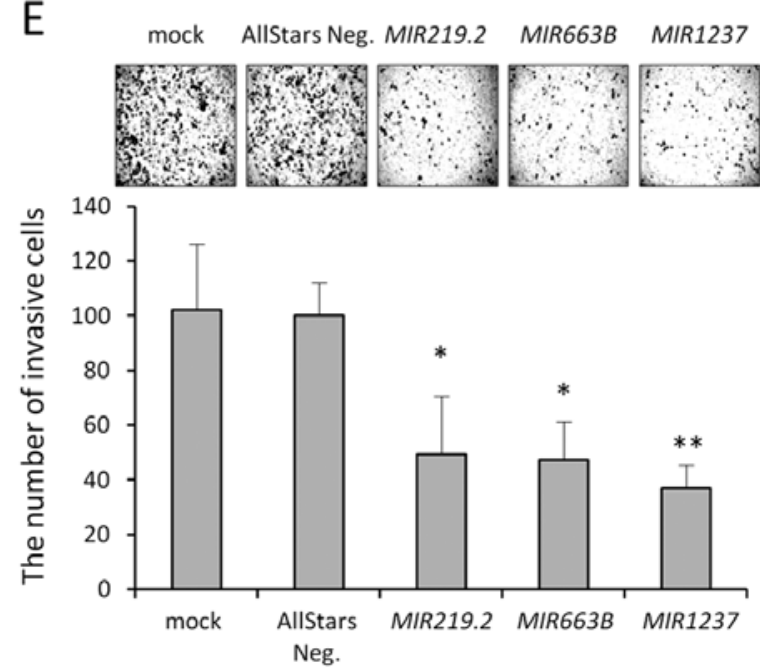

B

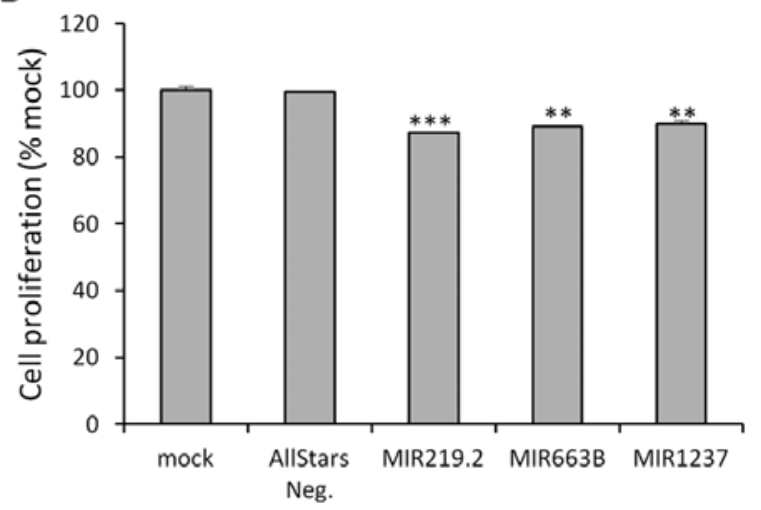

mock AllStars Neg. MIR219.2 MIR663B MIR1237

D
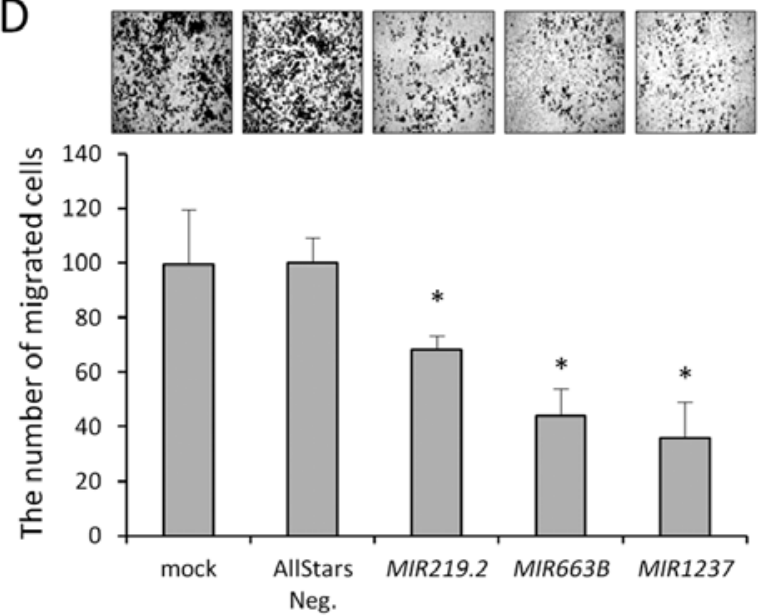

$\mathrm{F}$

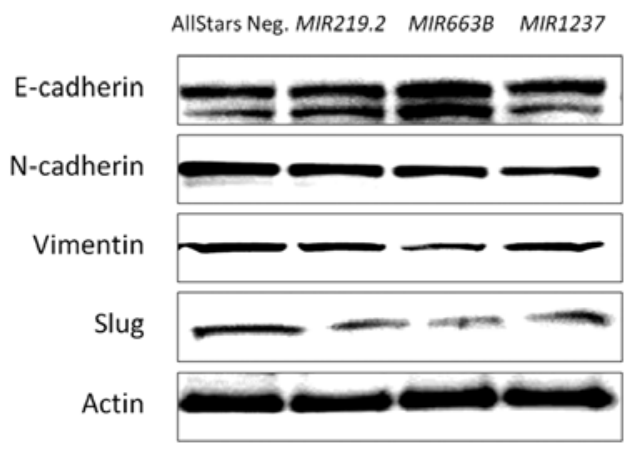

Figure 4. Functional analyses of MIR219.2, MIR663B and MIR1237 in AGS cells. (A) Growth curves and (B) MTT assays of AGS mock-treated cells and AGS cells transfected with non-targeting negative control miRNA (AllStars neg.) or MIR219.2, MIR663B or MIR1237 mimics. (C) Wound-healing assay for AGS cells transfected with mock, non-targeting negative controls miRNA (AllStars neg.) or MIR219.2, MIR663B or MIR1237 mimics. Images were captured at $16 \mathrm{~h}$ after wounding. (D) Transwell migration and (E) invasion assays using AGS mock-treated cells and AGS cells transfected with non-coding negative control miRNA or MIR219.2, MIR663B or MIR1237 mimics. Representative fields of migratory and invasive cells on the membrane are shown. The bar graph represents the mean of three random microscopic fields per membrane, and the error bars represent the standard deviations (SDs). (F) Western blot analysis for the expression of EMT-associated proteins (E-cadherin, N-cadherin, vimentin and Slug) in MIR219.2, MIR663B or MIR1237 mimic-transfected AGS cells compared with non-targeting negative control miRNA transfection.

MIR1237, 156, 136 and 299 target genes were predicted, respectively. Since many target genes were identified, we selected several common genes for the three miRNAs (Table I). Therefore, to validate whether these candidate target genes are regulated by miRNAs, we analyzed the mRNA levels of these target genes using qRT-PCR in the AGS cells upon transfection of the miRNA mimics. We found that MIR219.2, MIR663B and MIR1237 mimics consistently depleted mRNA levels 
Table I. Target gene list for MIR219-2, MIR663B and MIR1237.

\begin{tabular}{|c|c|c|c|c|c|}
\hline \multirow[b]{2}{*}{ Gene } & \multicolumn{3}{|c|}{ miRNA } & \multirow[b]{2}{*}{ Accession no. } & \multirow[b]{2}{*}{ Function } \\
\hline & 219.2 & $663 \mathrm{~B}$ & 1237 & & \\
\hline ANKRD13C & $\mathrm{V}$ & & $\mathrm{V}$ & NM_030816.4 & Ankyrin repeat domain $13 \mathrm{C}$ \\
\hline C20orf112 & & $\mathrm{V}$ & $\mathrm{V}$ & NM_001256798.1; NM_080616.4 & $\begin{array}{l}\text { Chromosome } 20 \text { open reading } \\
\text { frame } 112\end{array}$ \\
\hline$C B X 5$ & & $\mathrm{~V}$ & $\mathrm{~V}$ & $\begin{array}{l}\text { NM_001127321.1; NM_001127322.1; } \\
\text { NM_012117.2 }\end{array}$ & Chromobox homolog 5 \\
\hline$C C D C 113$ & & $\mathrm{~V}$ & $\mathrm{~V}$ & NM_001142302.1; NM_014157.3 & $\begin{array}{l}\text { Coiled-coil domain } \\
\text { containing } 113\end{array}$ \\
\hline$C C N D 2$ & & $\mathrm{~V}$ & $\mathrm{~V}$ & NM_001759.3 & Cyclin D2 \\
\hline \multirow[t]{2}{*}{ CLCN5 } & & $\mathrm{V}$ & $\mathrm{V}$ & NM_000084.4; NM_001127898.3; & $\begin{array}{l}\text { Chloride channel, } \\
\text { voltage-sensitive } 5\end{array}$ \\
\hline & & & & $\begin{array}{l}\text { NM_001127899.3; NM_001272102.1; } \\
\text { NM_001282163.1 }\end{array}$ & \\
\hline CNNM1 & & $\mathrm{V}$ & V & NM_020348.2 & Cyclin M1 \\
\hline CT62 & $\mathrm{V}$ & & $\mathrm{V}$ & NM_001102658.1 & Cancer/Testis antigen 62 \\
\hline$C U X 1$ & & $\mathrm{~V}$ & $\mathrm{~V}$ & $\begin{array}{l}\text { NM_001202543.1; NM_001202544.1; } \\
\text { NM_001202545.1; NM_001202546.1; } \\
\text { NM_001913.3; NM_181500.2; NM_181552.3 }\end{array}$ & Cut-like homeobox 1 \\
\hline$D C C$ & $\mathrm{~V}$ & & $\mathrm{~V}$ & NM_005215.3 & Deleted in colorectal carcinoma \\
\hline$D C X$ & $\mathrm{~V}$ & $\mathrm{~V}$ & & $\begin{array}{l}\text { NM_000555.3; NM_001195553.1; } \\
\text { NM_178151.2; NM_178152.2; NM_178153.2 }\end{array}$ & Doublecortin \\
\hline$E R B B 3$ & $\mathrm{~V}$ & & $\mathrm{~V}$ & NM_001005915.1; NM_001982.3 & $\begin{array}{l}\text { V-Erb-B2 avian erythroblastic } \\
\text { leukemia viral oncogene } \\
\text { homolog } 3\end{array}$ \\
\hline IPO9 & $\mathrm{V}$ & & $\mathrm{V}$ & NM_018085.4 & Importin 9 \\
\hline NFIA & $\mathrm{V}$ & & $\mathrm{V}$ & $\begin{array}{l}\text { NM_001134673.3; NM_001145511.1; } \\
\text { NM_001145512.1; NM_005595.4 }\end{array}$ & Nuclear factor $\mathrm{I} / \mathrm{A}$ \\
\hline$N F I B$ & $\mathrm{~V}$ & & $\mathrm{~V}$ & $\begin{array}{l}\text { NM_001190737.1; NM_001190738.1; } \\
\text { NM_001282787.1; NM_005596.3 }\end{array}$ & Nuclear factor I/B \\
\hline NPEPPS & $\mathrm{V}$ & & $\mathrm{V}$ & NM_006310.3 & $\begin{array}{l}\text { Aminopeptidase puromycin } \\
\text { sensitive }\end{array}$ \\
\hline PMEPAl & $\mathrm{V}$ & & $\mathrm{V}$ & $\begin{array}{l}\text { NM_001255976.1; NM_020182.4; } \\
\text { NM_199169.2; NM_199170.2; NM_199171.2 }\end{array}$ & $\begin{array}{l}\text { Prostate transmembrane protein, } \\
\text { androgen induced } 1\end{array}$ \\
\hline PTPRT & $\mathrm{V}$ & & $\mathrm{V}$ & NM_007050.5; NM_133170.3 & $\begin{array}{l}\text { Protein tyrosine phosphatase, } \\
\text { receptor type, } T\end{array}$ \\
\hline$P U R B$ & $\mathrm{~V}$ & & $\mathrm{~V}$ & NM_033224.4 & $\begin{array}{l}\text { Purine-rich element binding } \\
\text { protein B }\end{array}$ \\
\hline RC3HI & $\mathrm{V}$ & & $\mathrm{V}$ & NM_172071.2 & $\begin{array}{l}\text { Ring finger and CCCH-type } \\
\text { domains } 1\end{array}$ \\
\hline SERPl & V & & $\mathrm{V}$ & NM_014445.3 & $\begin{array}{l}\text { Stress-associated endoplasmic } \\
\text { reticulum protein } 1\end{array}$ \\
\hline$S G I P 1$ & $\mathrm{~V}$ & & $\mathrm{~V}$ & NM_032291.2 & $\begin{array}{l}\text { SH3-domain GRB2-like } \\
\text { (endophilin) } \\
\text { interacting protein } 1\end{array}$ \\
\hline SMC1A & & $\mathrm{V}$ & $\mathrm{V}$ & NM_001281463.1; NM_006306.3 & $\begin{array}{l}\text { Structural maintenance of } \\
\text { chromosomes } 1 \mathrm{~A}\end{array}$ \\
\hline STAT5B & & $\mathrm{V}$ & $\mathrm{V}$ & NM_012448.3 & $\begin{array}{l}\text { Signal transducer and activator } \\
\text { of transcription } 5 \mathrm{~B}\end{array}$ \\
\hline USP47 & $\mathrm{V}$ & $\mathrm{V}$ & & NM_001282659.1; NM_017944.3 & Ubiquitin-specific peptidase 47 \\
\hline WASL & V & & $\mathrm{V}$ & NM_003941.3 & Wiskott-Aldrich syndrome-like \\
\hline YOD1 & $\mathrm{V}$ & & V & NM_001276320.1; NM_018566.3 & $\begin{array}{l}\text { YOD1 OTU deubiquinating } \\
\text { enzyme } 1 \text { homolog }\end{array}$ \\
\hline
\end{tabular}



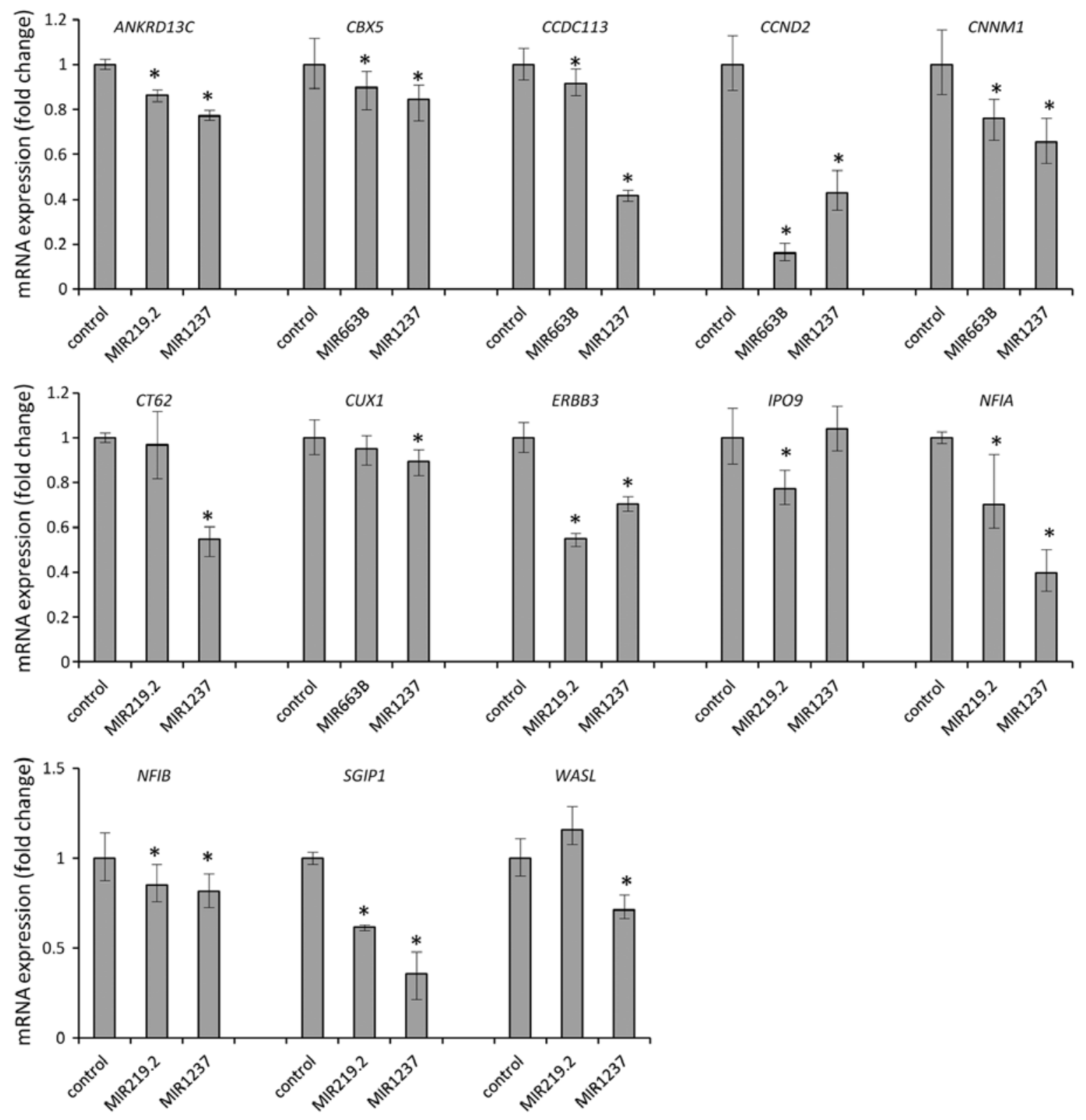

Figure 5. Candidate target genes are downregulated by MIR219.2, MIR663B or MIR1237 mimics. Quantitative RT-PCR was carried out in the AGS cell line transfected with non-targeting negative control miRNA (AllStars neg.) or MIR219.2, MIR663B or MIR1237 mimics. "P<0.05, indicates statistically significant decrease of gene expression levels compared to control.

of ANKRD13C, CBX5, CCDC113, CCND2, CNNM1, CT62, CUX1, ERBB3, IPO9, NFIA, NFIB, SGIPI and WASL (Fig. 5). After we validate this, we identified 13 candidates as bona fide targets of MIR219.2, MIR663B and MIR1247 in gastric cancer. All 13 candidate genes were downregulated by ectopic expression of MIR219.2, MIR663B and MIR1247 in the AGS cells which suggest that expression of the target genes we identified is regulated by these miRNAs.

\section{Discussion}

miRNAs are important regulatory molecules that modulate gene expression in both developmental and disease processes. Their regulation is, therefore, a critical component in understanding each biological context (23). Dysregulation of miRNA expression is commonly observed in a wide variety of cancers, and epigenetic mechanisms have been shown to be key mediators underlying the downregulation of miRNA expression. To screen for epigenetically silenced miRNA genes in gastric cancer, we first performed a microarray analysis to identify miRNAs upregulated by demethylation and histone deacetylase inhibition. There are several miRNAs that have been found to be regulated by DNA hypermethylation and could have tumor-suppressive roles in various cancers.

In recent years, accumulated evidence that the transcription of a handful of miRNAs in cancer is regulated by DNA methylation has been reported. For example, MIR 127 has been found to be activated by epigenetic drug treatment in cancer cells (15). In addition, methylation of MIR9 and MIR148a has been observed in human metastatic cancer cell lines (24), and MIR203 is epigenetically silenced in hematopoietic 
malignancies, which leads to enhanced expression of ABL1 and BCR-ABL1 (25). Recently, MIR34a reportedly acts as a tumor suppressor in colon cancer and neuroblastoma $(25,26)$. All three MIR34 family members are directly regulated by p53, and ectopic expression of MIR34s induces cell cycle arrest and/or apoptosis in human cancer cells $(5,27,28)$. Conversely, expression of MIR34s is frequently downregulated in human malignancies, including lung, colon and ovarian cancers (26-29). Very recently we also first reported that transcription of MIR941, MIRI247 and their target genes are regulated by DNA methylation in gastric cancers (18). In addition, Lujambio et al (24) identified MIR34b/c methylation by screening cell lines derived from metastatic colon cancer, melanoma, and head and neck cancer, and Corney et al (28) recently reported downregulation of $M I R 34 \mathrm{~b} / \mathrm{c}$ in metastatic ovarian cancer, which suggests that inactivation of MIR34b/c may be associated with cancer metastasis.

In the present study, ectopic expression of MIR219.2, MIR663B and MIR 1237 reduced cell growth, proliferation, migration and invasion, suggesting that these miRNAs have tumor-suppressive effects in gastric cancer cells. Moreover, we support more strongly a tumor-suppressive role as evidenced by decreased mesenchymal phenotypes using mesenchymal cell markers, such as $\mathrm{N}$-cadherin and vimentin.

We predicted target genes using the TargetScan and miRBase databases and found 13 candidate genes that were validated by qRT-PCR among the more than 100 predicted target genes. These 13 genes could be potential targets of MIR219.2, MIR663B and MIR1237. Although these genes were among the predicted targets, we were interested in how these genes are associated within the cellular pathway network. Networks of collected target genes were analyzed together by GeneMANIA and visualized by Cytoscape version 3.0.2. Twenty-four target genes were found to be related to 20 neighbor genes, and there are 170 total interaction links. In particular, the functions of networks are categorized as follows: cohesin complex, protein-DNA complex, regulation of anion transport, chloride channel activity, chromosome condensation, anion channel activity, chloride transmembrane transporter activity, excretion, chloride transport and nuclear chromosome (data not shown). These results support the hypothesis that selected target genes may play various important roles and are intimately connected with each other. Therefore, to understand the possible roles of selected target genes, signal pathways and the relationship with cancers were predicted using KEGG and GeneCards databases. These data suggest that target genes of MIR219.2, MIR663B and MIRI237 are related to each other through critical cancer pathways; therefore, further study is necessary to understand the biological interactions between miRNAs and target genes in cancer.

Among the candidate target genes of MIR219.2 and MIR1237, the receptor tyrosine kinase ERBB3 (epidermal growth factor receptor family) has been reported to be targeted by several miRNAs (MIR199a/125b, MIR143 and MIR145) in various types of cancer (30-32). High levels of ERBB3 are strongly associated with tumor progression and poor outcome in gastric cancer patients $(33,34)$. CCND2 (cyclin D2) is known as a proto-oncogene, and overexpression of CCND2 is closely correlated with progression in gastric cancer $(35,36)$. Similar to our study, $C C N D 2$ was found to be downregulated by $M I R 1$, and then cell proliferation, migration and invasion were reduced in thyroid cancer carcinoma cells (37). In addition, CCND2 is also targeted by MIR206 and MIR29, which results in the suppression of cell growth in gastric cancer $(38,39)$.

In summary, we demonstrated that MIR219.2, MIR663B and MIR 1237 are silenced in gastric cancer cell lines by DNA hypermethylation. Our expression and functional studies suggest that ectopic expression of these miRNAs has tumor-suppressive effects in the AGS gastric cancer cell line by decreasing mesenchymal phenotypes. Moreover, their molecular targets are associated with multiple biological pathways according to our bioinformatic analyses. Therefore, our functional data on MIR219.2, MIR663B and MIR1237 target genes is a compelling lead, but the detailed relationships between many more target genes and the three miRNAs will require further study. More importantly, we demonstrated that such abnormal epigenetic silencing occurs in gastric cancer and may be useful in developing new potential therapeutic tools for this disease.

\section{Acknowledgements}

This study was supported by the National R\&D Program (nos. 50591-2015) through the Dongnam Institute of Radiological and Medical Sciences (DIRAMS) funded by the Ministry of Science, ICT and Future Planning (MSIP) of the Korean government.

\section{References}

1. Bartel DP: MicroRNAs: Genomics, biogenesis, mechanism, and function. Cell 116: 281-297, 2004.

2. Lewis BP, Shih IH, Jones-Rhoades MW, Bartel DP and Burge CB: Prediction of mammalian microRNA targets. Cell 115: 787-798, 2003.

3. Lewis BP, Burge CB and Bartel DP: Conserved seed pairing, often flanked by adenosines, indicates that thousands of human genes are microRNA targets. Cell 120: 15-20, 2005.

4. He L and Hannon GJ: MicroRNAs: Small RNAs with a big role in gene regulation. Nat Rev Genet 5: 522-531, 2004.

5. He L, He X, Lim LP, de Stanchina E, Xuan Z, Liang Y, Xue W, Zender L, Magnus J, Ridzon D, et al: A microRNA component of the p53 tumour suppressor network. Nature 447: 1130-1134, 2007.

6. Calin GA and Croce CM: MicroRNA signatures in human cancers. Nat Rev Cancer 6: 857-866, 2006.

7. Dalmay T and Edwards DR: MicroRNAs and the hallmarks of cancer. Oncogene 25: 6170-6175, 2006.

8. Lu J, Getz G, Miska EA, Alvarez-Saavedra E, Lamb J, Peck D, Sweet-Cordero A, Ebert BL, Mak RH, Ferrando AA, et al: MicroRNA expression profiles classify human cancers. Nature 435: 834-838, 2005.

9. Takamizawa J, Konishi H, Yanagisawa K, Tomida S, Osada H, Endoh H, Harano T, Yatabe Y, Nagino M, Nimura Y, et al: Reduced expression of the let-7 microRNAs in human lung cancers in association with shortened postoperative survival. Cancer Res 64: 3753-3756, 2004.

10. Iorio MV, Ferracin M, Liu CG, Veronese A, Spizzo R, Sabbioni S, Magri E, Pedriali M, Fabbri M, Campiglio M, et al: MicroRNA gene expression deregulation in human breast cancer. Cancer Res 65: 7065-7070, 2005.

11. Yoon SO, Chun SM, Han EH, Choi J, Jang SJ, Koh SA, Hwang S and $\mathrm{Yu}$ E: Deregulated expression of microRNA-221 with the potential for prognostic biomarkers in surgically resected hepatocellular carcinoma. Hum Pathol 42: 1391-1400, 2011.

12. Mraz M and Pospisilova S: MicroRNAs in chronic lymphocytic leukemia: From causality to associations and back. Expert Rev Hematol 5: 579-581, 2012. 
13. Calin GA, Dumitru CD, Shimizu M, Bichi R, Zupo S, Noch E, Aldler H, Rattan S, Keating M, Rai K, et al: Frequent deletions and down-regulation of micro-RNA genes miR15 and miR16 at $13 q 14$ in chronic lymphocytic leukemia. Proc Natl Acad Sci USA 99: 15524-15529, 2002.

14. Calin GA, Ferracin M, Cimmino A, Di Leva G, Shimizu M, Wojcik SE, Iorio MV, Visone R, Sever NI, Fabbri M, et al: A MicroRNA signature associated with prognosis and progression in chronic lymphocytic leukemia. N Engl J Med 353: 1793-1801, 2005.

15. Saito Y, Liang G, Egger G, Friedman JM, Chuang JC, Coetzee GA and Jones PA: Specific activation of microRNA-127 with downregulation of the proto-oncogene BCL6 by chromatin-modifying drugs in human cancer cells. Cancer Cell 9: 435-443, 2006.

16. Nakamura T, Canaani E and Croce CM: Oncogenic All1 fusion proteins target Drosha-mediated microRNA processing. Proc Natl Acad Sci USA 104: 10980-10985, 2007.

17. Parkin DM: Global cancer statistics in the year 2000. Lancet Oncol 2: 533-543, 2001

18. Kim JG, Kim TO, Bae JH, Shim JW, Kang MJ, Yang K, Ting AH and Yi JM: Epigenetically regulated MIR941 and MIR1247 target gastric cancer cell growth and migration. Epigenetics 9: 1018-1030, 2014

19. Ushijima T, Nakajima T and Maekita T: DNA methylation as a marker for the past and future. J Gastroenterol 41: 401-407, 2006

20. Ando T, Yoshida T, Enomoto S, Asada K, Tatematsu M, Ichinose M, Sugiyama T and Ushijima T: DNA methylation of microRNA genes in gastric mucosae of gastric cancer patients: its possible involvement in the formation of epigenetic field defect. Int J Cancer 124: 2367-2374, 2009.

21. Yan $\mathrm{H}$, Choi AJ, Lee $\mathrm{BH}$ and Ting $\mathrm{AH}$ : Identification and functional analysis of epigenetically silenced microRNAs in colorectal cancer cells. PLoS One 6: e20628, 2011.

22. Thiery JP: Epithelial-mesenchymal transitions in tumour progression. Nat Rev Cancer 2: 442-454, 2002.

23. Esquela-Kerscher A and Slack FJ: OncomiRs - microRNAs with a role in cancer. Nat Rev Cancer 6: 259-269, 2006.

24. Lujambio A, Calin GA, Villanueva A, Ropero S, Sánchez-Céspedes M, Blanco D, Montuenga LM, Rossi S, Nicoloso MS Faller WJ, et al: A microRNA DNA methylation signature for human cancer metastasis. Proc Natl Acad Sci USA 105: 13556-13561, 2008.

25. Welch C, Chen Y and Stallings RL: MicroRNA-34a functions as a potential tumor suppressor by inducing apoptosis in neuroblastoma cells. Oncogene 26: 5017-5022, 2007.

26. Tazawa $H$, Tsuchiya $N$, Izumiya $M$ and Nakagama $H$ : Tumor-suppressive MIR34a induces senescence-like growth arrest through modulation of the E2F pathway in human colon cancer cells. Proc Natl Acad Sci USA 104: 15472-15477, 2007.

27. Bommer GT, Gerin I, Feng Y, Kaczorowski AJ, Kuick R, Love RE, Zhai Y, Giordano TJ, Qin ZS, Moore BB, et al: p53-mediated activation of miRNA34 candidate tumor-suppressor genes. Curr Biol 17: 1298-1307, 2007.
28. Corney DC, Flesken-Nikitin A, Godwin AK, Wang W and Nikitin AY: microRNA-34b and microRNA-34c are targets of p53 and cooperate in control of cell proliferation and adhesion-independent growth. Cancer Res 67: 8433-8438, 2007.

29. Toyota M, Suzuki H, Sasaki Y, Maruyama R, Imai K, Shinomura Y and Tokino T: Epigenetic silencing of microRNA-34b/c and B-cell translocation gene 4 is associated with $\mathrm{CpG}$ island methylation in colorectal cancer. Cancer Res 68: 4123-4132, 2008.

30. He J, Xu Q, Jing Y, Agani F, Qian X, Carpenter R, Li Q, Wang XR, Peiper SS, Lu Z, et al: Reactive oxygen species regulate ERBB2 and ERBB3 expression via miR-199a/125b and DNA methylation. EMBO Rep 13: 1116-1122, 2012.

31. Lei H, Zou D, Li Z, Luo M, Dong L, Wang B, Yin H, Ma Y, Liu C, Wang F, et al: MicroRNA-219-2-3p functions as a tumor suppressor in gastric cancer and is regulated by DNA methylation. PLoS One 8: e60369, 2013.

32. Yan X, Chen X, Liang H, Deng T, Chen W, Zhang S, Liu M, Gao X, Liu Y,Zhao C, et al: miR-143 and miR-145 synergistically regulate ERBB3 to suppress cell proliferation and invasion in breast cancer. Mol Cancer 13: 220, 2014.

33. Hayashi M, Inokuchi M, Takagi Y, Yamada H, Kojima K, Kumagai J, Kawano T and Sugihara K: High expression of HER3 is associated with a decreased survival in gastric cancer. Clin Cancer Res 14: 7843-7849, 2008.

34. Begnami MD, Fukuda E, Fregnani JH, Nonogaki S, Montagnini AL, da Costa WL Jr and Soares FA: Prognostic implications of altered human epidermal growth factor receptors (HERs) in gastric carcinomas: HER2 and HER3 are predictors of poor outcome. J Clin Oncol 29: 3030-3036, 2011.

35. Oshimo Y, Nakayama H, Ito R, Kitadai Y, Yoshida K, Chayama K and Yasui W: Promoter methylation of cyclin D2 gene in gastric carcinoma. Int J Oncol 23: 1663-1670, 2003.

36. Takano Y, Kato Y, Masuda M, Ohshima Y and Okayasu I: Cyclin D2, but not cyclin D1, overexpression closely correlates with gastric cancer progression and prognosis. J Pathol 189: 194-200, 1999.

37. Leone V, D'Angelo D, Rubio I, de Freitas PM, Federico A, Colamaio M, Pallante P, Medeiros-Neto G and Fusco A: MiR-1 is a tumor suppressor in thyroid carcinogenesis targeting CCND2, CXCR4, and SDF-1alpha. J Clin Endocrinol Metab 96: E1388-E1398, 2011.

38. Zhang L, Liu X, Jin H, Guo X, Xia L, Chen Z, Bai M, Liu J, Shang $\mathrm{X}, \mathrm{Wu} \mathrm{K}$, et al: miR-206 inhibits gastric cancer proliferation in part by repressing cyclinD2. Cancer Lett 332: 94-101, 2013.

39. Gong J, Li J, Wang Y, Liu C, Jia H, Jiang C, Wang Y, Luo M, Zhao H, Dong L, et al: Characterization of microRNA-29 family expression and investigation of their mechanistic roles in gastric cancer. Carcinogenesis 35: 497-506, 2014. 